\title{
DETERMINATION OF TRANSPEDICULAR SCREW PARAMETERS WITH THE HELP OF PEDICLE MORPHOMETRY OF THORACIC VERTEBRAE FOR SAFE TRANSPEDICULAR SCREW FIXATION - A CADAVERIC STUDY
}

Gangadhara 1

HOW TO CITE THIS ARTICLE:

Gangadhara. "Determination of transpedicular screw parameters with the help of pedicle morphometry of thoracic vertebrae for safe transpedicular screw fixation - a cadaveric study". Journal of Evolution of Medical and Dental Sciences 2013; Vol2, Issue 36, September 9; Page: 6807-6815.

ABSTRACT: CONTEXT (BACKGROUND): It is very essential for a surgeon to have the knowledge of pedicle parameters for stabilizing the thoracic vertebra by Transpedicular screw fixation. AIM: To measure the anterior pedicle diameter, posterior pedicle diameter, pedicle diameter at isthmus (minimum pedicle diameter), sagittal pedicle diameter, pedicle length and chord length of all twelve thoracic vertebrae in south Indian population and to determine the length and diameter of the screw for accurate and hazardless surgery. SETTINGS AND DESIGN: A cadaveric study was done in a medical institution. METHODS AND MATERIALS: Study was done on 20 cadaveric specimens of thoracic region of vertebral column. All the thoracic vertebrae (T1-T12) were separated in all 20 specimens, and in total 480 pedicles were studied for anterior pedicle diameter, posterior pedicle diameter, pedicle diameter at isthmus, sagittal pedicle diameter, pedicle length, and chord length and with the help of these statistics the diameter and length of the screw were determined. STATISTICAL ANALYSIS USED: Simple analysis was used. RESULTS: Pedicle diameter at isthmus (minimum diameter) at $\mathrm{T} 1$ is $6.98 \pm 1.15$, which decreases caudally to minimum at $\mathrm{T} 4(3.90 \pm 0.80)$ then gradually increases caudally to a maximum at T12 (7.88 \pm 1.38$)$. Anterior pedicle diameter at T1 is $7.56 \pm 1.09$ which decreases caudally to minimum value at T5 $(5.28 \pm 0.92)$, and again increases caudally reaching maximum value at $\mathrm{T} 12$ (9.04 \pm 1.63$)$. Posterior pedicle diameter at $\mathrm{T} 1$ is $(7.74 \pm 1.34)$ which decreases caudally to minimum at T4 $(4.70 \pm 1.00)$, and increases caudally to a maximum value at T12 $(8.51 \pm 1.20)$. Sagittal diameter at isthmus is gradually increasing from minimum at $\mathrm{T} 1(8.47 \pm 0.87)$ to maximum at $\mathrm{T} 12(15.40 \pm 2.20)$. The Chord length is minimum at $\mathrm{T} 1$ $(31.88 \pm 2.67)$ and gradually increases caudally to a maximum at $\mathrm{T} 12(45.57 \pm 3.86)$. The Pedicle length is minimum at T1 $(4.84 \pm 0.85)$ and increases caudally to a maximum at T8 $(6.14 \pm 0.99)$ and again decreases caudally and at T12 Pedicle length is (5.15 \pm 0.64$)$. CONCLUSIONS: Spinal surgeons, neurosurgeons or orthopaedic surgeons should have the essential knowledge of pedicle diameter and chord length for selecting the appropriate Transpedicular screw.

KEY WORDS: Thoracic pedicle, Pedicle diameter, Chord length, Transpedicular screw, pedicle morphometry

INTRODUCTION: The pedicles of thoracic vertebrae are tube like bony structures that connect the anterior and posterior columns of pedicle [1]. The transpedicular screw-rod fixation for spinal stabilization through the posterior approach is the recent and evolving technique. The transpedicular screw-rod fixation technique in thoracic spine has been used successfully in various clinical approaches such as fracture, segmental instability, hyper kyphosis, scoliosis, infection and tumours. However, insertion of thoracic pedicle screws is technically challenging and is associated 
with risk of damaging various neurologic and vascular structures like superior intercostal vessels, oesophagus, azygous vein, inferior venacava, thoracic duct, aorta, lungs, sympathetic chain and spinal cord with duramater. These potential risks are due to the varying pedicle dimensions and orientation at every level of the thoracic vertebrae, also differences in thickness and strength of the pedicle between adults and elderly individuals; also makes the technique even more complex [2][3]. And risks can be made minimal only with proper knowledge of technique, pedicle diameter and screw diameter and length. Hence we feel the spinal surgeon, neurosurgeons and orthopaedic surgeons should know the correct diameter and length of the Transpedicular screw and measurements of pedicle for the emergency as well as planned Transpedicular screw fixation of thoracic vertebrae

MATERIALS AND METHODS: Thoracic part of the vertebral column from 20 well embalmed cadavers aged around 40 to 65 years which are free of any spinal disorders were separated and labeled from 1 to 20 serially. The vertebrae were separated and soft tissue was removed by clean and meticulous dissection and immediately labeled with the number corresponding with the number of thoracic vertebra in the body. The following parameters of the thoracic vertebrae were measured with the help of digital vernier calipers in millimeters and immediately noted in the preformed proforma.

- Anterior pedicle diameter at the junction of pedicle with the body of vertebra (APD)

- Posterior pedicle diameter at the junction of pedicle with the lamina (PPD)

- Pedicle diameter at isthmus (minimum diameter) (PDI)

- Sagittal pedicle diameter at the isthmus(SDI)

- Chord length(co-axial distance from the lamina to anterior vertebral cortex along the axis of pedicle) (CL)

- Pedicle length (between the lamina and vertebral body) (PL)

There was not much of difference statistically in the measurements done between right and left side pedicles so data of both right and left side pedicles were pooled and analysed.

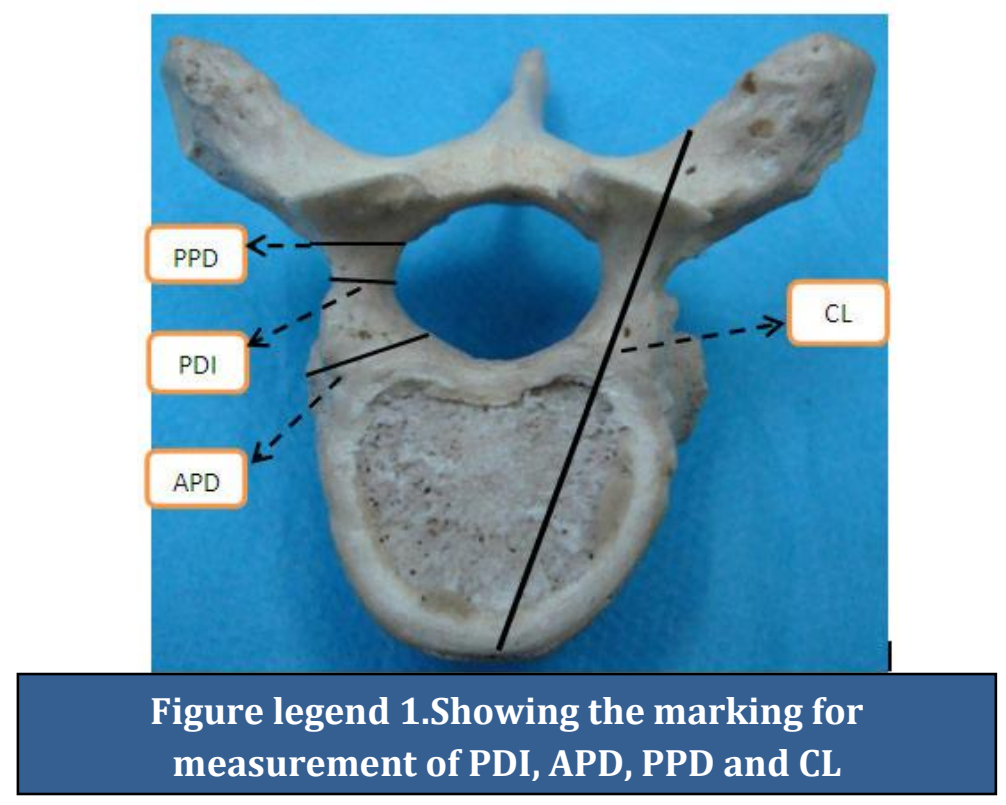




\section{ORIGINAL ARTICLE}

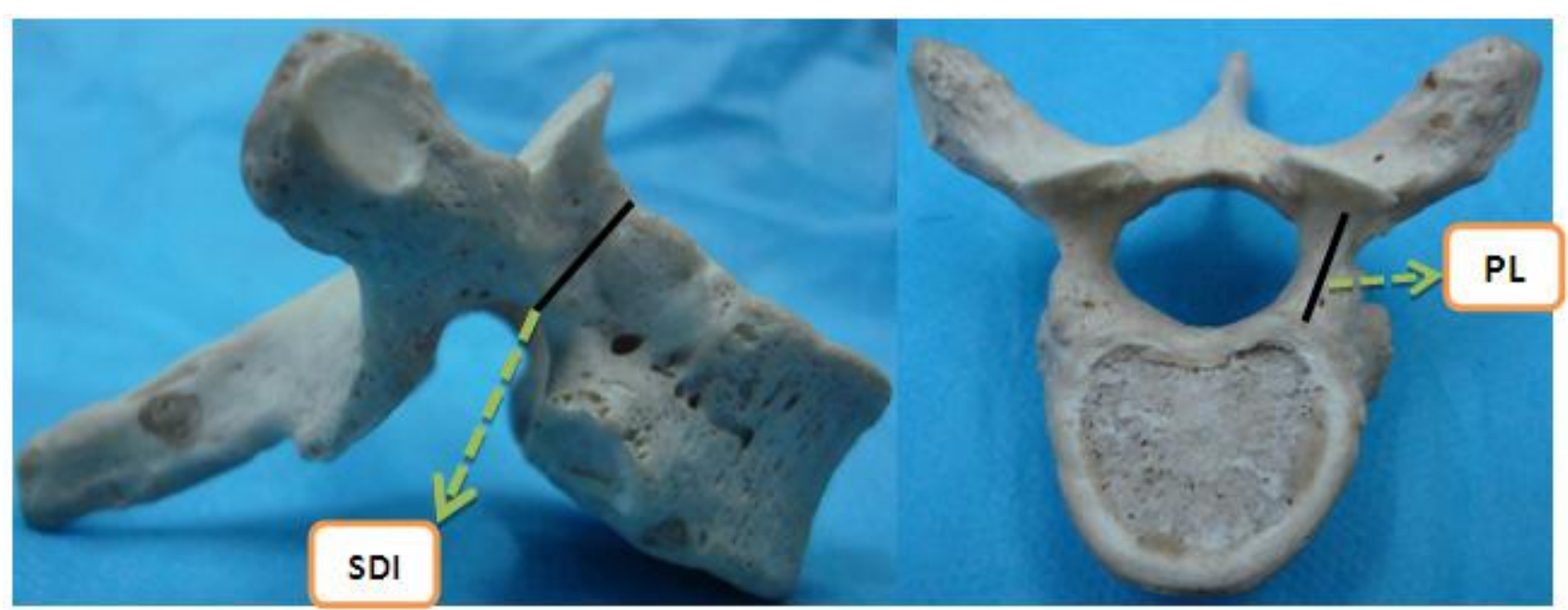

Figure legend 2 \& 3. Showing marking for measuring SDIand PL respectively

\section{RESULTS:}

Pedicle diameter at isthmus (minimum pedicle diameter) (PDI): Tabulation of the PDI of 12 thoracic vertebrae is shown in table 1 . The Range and Mean PDI with SD of all thoracic vertebrae are shown. The PDI at T1 is $(6.98 \pm 1.15)$ which goes on decreases in downward direction and minimum value reached at $\mathrm{T} 4(3.90 \pm 0.80)$ and goes on increases downwards and maximum value found at T12 (7.88 \pm 1.38$)$.

\begin{tabular}{|c|c|c|}
\hline Vertebral level & Range & Mean \pm SD \\
\hline T1 & $5.15-8.85$ & $6.98 \pm 1.15$ \\
\hline T2 & $3.55-7.85$ & $5.62 \pm 1.08$ \\
\hline T3 & $2.83-5.78$ & $4.43 \pm 0.75$ \\
\hline T4 & $2.6-5.52$ & $3.90 \pm 0.80$ \\
\hline T5 & $2.7-5.15$ & $3.93 \pm 0.71$ \\
\hline T6 & $2.54-6.69$ & $4.28 \pm 1.04$ \\
\hline T7 & $2.7-7.21$ & $4.77 \pm 1.26$ \\
\hline T8 & $3.2-7.02$ & $4.95 \pm 1.13$ \\
\hline T9 & $3.75-7.93$ & $5.59 \pm 1.13$ \\
\hline T10 & $3.2-9.7$ & $6.66 \pm 1.44$ \\
\hline T11 & $5.15-10.14$ & $7.55 \pm 1.19$ \\
\hline T12 & $5.87-10.48$ & $7.88 \pm 1.38$ \\
\hline \multicolumn{2}{|c|}{ Table 1: Pedicle diameter at isthmus }
\end{tabular}

SD-Standard deviation

Anterior pedicle diameter (APD): Tabulation of the APD of 12 thoracic vertebrae is shown in table 2. The Range and Mean APD with SD of all thoracic vertebrae are shown. The mean APD at T1 is 
$7.56 \pm 1.09$ which goes on decreasing and reaching minimum value at T5 (5.28 \pm 0.92$)$, and again goes on increases downwards towards T12 reaching maximum value $(9.04 \pm 1.63)$.

\begin{tabular}{|c|c|c|}
\hline Vertebral level & Range & Mean \pm SD \\
\hline T1 & $5.62-9.3$ & $7.56 \pm 1.09$ \\
\hline T2 & $4.2-8.5$ & $6.08 \pm 1.07$ \\
\hline T3 & $4.18-7.65$ & $5.55 \pm 0.96$ \\
\hline T4 & $3.6-8.69$ & $5.32 \pm 1.23$ \\
\hline T5 & $3.1-6.7$ & $5.28 \pm 0.92$ \\
\hline T6 & $3.3-7.35$ & $5.6 \pm 1.08$ \\
\hline T7 & $3.53-8.46$ & $5.95 \pm 1.39$ \\
\hline T8 & $4.16-7.8$ & $6.09 \pm 1.04$ \\
\hline T9 & $4.48-9.67$ & $6.97 \pm 1.46$ \\
\hline T10 & $5.11-10.48$ & $8.03 \pm 1.51$ \\
\hline T11 & $6.15-11.45$ & $8.91 \pm 1.28$ \\
\hline T12 & $6.16-11.93$ & $9.04 \pm 1.63$ \\
\hline
\end{tabular}

\section{Table 2: Anterior pedicle diameter}

SD-Standard deviation

Posterior pedicle diameter (PPD): Tabulation of the PPD of 12 thoracic vertebrae is shown in table 3. The Range and Mean PPD with SD of all thoracic vertebrae are shown. The PPD at T1 is $(7.74 \pm 1.34)$ which goes on decreases as we move downwards and reaches minimum at $\mathrm{T} 4$ $(4.70 \pm 1.00)$, and goes on increases in downward direction to a maximum value at T12 (8.51 \pm 1.20$)$.

\begin{tabular}{|c|c|c|}
\hline Vertebral level & Range & Mean \pm SD \\
\hline T1 & $5.5-10.02$ & $7.74 \pm 1.34$ \\
\hline T2 & $4.05-9.4$ & $6.23 \pm 1.35$ \\
\hline T3 & $3.64-7.05$ & $5.30 \pm 0.91$ \\
\hline T4 & $3.2-7.1$ & $4.70 \pm 1.00$ \\
\hline T5 & $3.1-6.92$ & $4.79 \pm 0.91$ \\
\hline T6 & $3.2-8.19$ & $5.18 \pm 1.24$ \\
\hline T7 & $3.5-8.19$ & $5.53 \pm 1.25$ \\
\hline T8 & $4.15-7.45$ & $5.75 \pm 1.02$ \\
\hline T9 & $4.2-8.75$ & $6.29 \pm 1.34$ \\
\hline T10 & $5.05-10.16$ & $7.43 \pm 1.35$ \\
\hline T11 & $4.72-11.52$ & $8.21 \pm 1.36$ \\
\hline T12 & $6.5-11.02$ & $8.51 \pm 1.20$ \\
\hline
\end{tabular}

Table 3: Posterior pedicle diameter

SD-Standard deviation 
Sagittal pedicle diameter at isthmus (SDI): Tabulation of SDI of 12 thoracic vertebrae is shown in table 4. The Range and Mean SDI with SD of all thoracic vertebrae are shown. The SDI is gradually increasing from minimum at T1 $(8.47 \pm 0.87)$ to maximum at $\mathrm{T} 12(15.40 \pm 2.20)$.

\begin{tabular}{|c|c|c|}
\hline Vertebral level & Range & Mean \pm SD \\
\hline T1 & $6.85-10.6$ & $8.47 \pm 0.87$ \\
\hline T2 & $7.82-12.58$ & $9.96 \pm 1.23$ \\
\hline T3 & $6-12.8$ & $9.65 \pm 1.38$ \\
\hline T4 & $8.4-12.67$ & $10.18 \pm 1.21$ \\
\hline T5 & $7.75-12.95$ & $10.14 \pm 1.25$ \\
\hline T6 & $7.31-13.13$ & $10.30 \pm 1.43$ \\
\hline T7 & $7.94-13.81$ & $10.91 \pm 1.47$ \\
\hline T8 & $8.55-14.28$ & $11.72 \pm 1.38$ \\
\hline T9 & $8.1-16.25$ & $12.74 \pm 1.77$ \\
\hline T10 & $11.04-18.2$ & $14.01 \pm 2.00$ \\
\hline T11 & $10.27-19.09$ & $15.35 \pm 2.20$ \\
\hline T12 & $11.17-19.26$ & $15.40 \pm 2.20$ \\
\hline Table 4:
\end{tabular}

Table 4: Sagittal pedicle diameter

SD-Standard deviation

Chord length (co-axial distance from the lamina to anterior vertebral cortex along the axis of pedicle) (CL): Tabulation of the CL of 12 thoracic vertebrae is shown in table 5. The Range and Mean CL with SD of all thoracic vertebrae are shown. The CL is minimum at T1 (31.88 \pm 2.67$)$ and gradually increased downwards and maximum at T12 (45.57 \pm 3.86$)$.

\begin{tabular}{|c|c|c|}
\hline Vertebral level & Range & Mean \pm SD \\
\hline T1 & $28.23-36.92$ & $31.88 \pm 2.67$ \\
\hline T2 & $30.33-39.65$ & $34.33 \pm 2.96$ \\
\hline T3 & $31.95-42.6$ & $36.15 \pm 3.25$ \\
\hline T4 & $34.09-41.75$ & $37.96 \pm 2.52$ \\
\hline T5 & $33.75-44.03$ & $39.26 \pm 2.91$ \\
\hline T6 & $35.4-46.72$ & $41.04 \pm 3.19$ \\
\hline T7 & $38.45-48.7$ & $43.41 \pm 2.86$ \\
\hline T8 & $38.00-49.88$ & $43.74 \pm 3.13$ \\
\hline T9 & $38.43-50.47$ & $44.48 \pm 3.51$ \\
\hline T10 & $37.5-50.18$ & $43.87 \pm 3.36$ \\
\hline T11 & $38.2-50.8$ & $43.83 \pm 3.39$ \\
\hline T12 & 33.62-50.5 & $44.57 \pm 3.86$ \\
\hline \multicolumn{2}{|c|}{ Table 5: Chord length } \\
\hline
\end{tabular}

SD-Standard deviation 
Pedicle length (PL): Tabulation of PL of 12 thoracic vertebrae is shown in table 6. The Range and Mean PL with SD of all thoracic vertebrae are shown. The PL is minimum at T1 (4.84 \pm 0.85$)$ and increases in downward direction to a maximum at T8 (6.14 \pm 0.99$)$ and again decreases downwards and at T12 PL is $(5.15 \pm 0.64)$.

\begin{tabular}{|c|c|c|}
\hline Vertebral level & Range & Mean \pm SD \\
\hline T1 & $3.78-6.8$ & $4.84 \pm 0.85$ \\
\hline T2 & $3.66-7.2$ & $5.23 \pm 1.10$ \\
\hline T3 & $4.42-8.62$ & $5.60 \pm 1.05$ \\
\hline T4 & $3.91-7.15$ & $5.68 \pm 0.89$ \\
\hline T5 & $4.15-7.31$ & $5.86 \pm 0.98$ \\
\hline T6 & $4.51-7.39$ & $5.94 \pm 0.86$ \\
\hline T7 & $4.86-8.05$ & $6.01 \pm 0.67$ \\
\hline T8 & $4.9-8.57$ & $6.14 \pm 0.99$ \\
\hline T9 & $4.96-9.1$ & $6.00 \pm 1.13$ \\
\hline T10 & $4.3-6.23$ & $5.27 \pm 0.57$ \\
\hline T11 & $4.18-6.75$ & $5.19 \pm 0.75$ \\
\hline T12 & $4.1-6.5$ & $5.15 \pm 0.64$ \\
\hline \multicolumn{3}{|c|}{ Table 6: Pedicle length } \\
\hline \multicolumn{3}{|c}{} \\
\hline \multicolumn{3}{|c|}{}
\end{tabular}

DISCUSSION: Transpedicular screw fixation in the thoracic spine remains an extremely debated topic with any spinal surgeon [4]. Pedicle screw, rod/plate instrumentation has become a popular and accepted method of dorsal spinal stabilization [2]. It is considered biomechanically superior and offers an alternative to the traditional hook and rod instrumentation. Transpedicular screw devices provide secure attachment for posterior spinal fixation technique. Screw design details, biomechanics and implantation safety depend upon anatomic constraints, especially from the pedicle and body [5]. The most important parameters of pedicle influencing the screw placement are: pedicle diameter at isthmus (minimal pedicle diameter) and chord length as these decides the upper limit of diameter and length of the transpedicular screw and also they influence the screw bone interface strength.

The pedicle diameter at isthmus (minimal diameter) (PDI) is the parameter which decides the diameter of the transpedicular screw should be used. The mean PDI of our study at various levels were comparable with the results of Datir et al, who has done the study on Indian population, and suggests that a $4 \mathrm{~mm}$ screw should be used carefully at mid-thoracic levels [6]. Our study results are also comparable to other studies $[3,4,7,8,9 \& 10]$. The PDI greatly diminished at T4-T6 levels, 33\% of T4 and $25 \%$ of T5 pedicle were smaller than $4.5 \mathrm{~mm}$ in diameter, where standard pedicle screw was used [4 \& 11]. In our study we found minimum pedicle diameter at T4-T5 with a mean of $3.90 \pm 0.80$ and $3.93 \pm 0.71$ respectively. Hence we suggest use of $3.5 \mathrm{~mm}$ diameter screw at these levels is safe. The parameters of screw at other levels also shown in the master table 7. 
Anterior and posterior diameters of pedicle are not much influencing parameters for the determining the transpedicular screw diameter. We have presented in our study as no authors have studied these two parameters.

Chord length is the parameter that directly decides the safe length of the transpedicular screw for avoiding any visceral or neurovascular catastrophes [3, 7 \& 11].Shorter CL of upper thoracic spine, inadequate fluoroscopic visualization during surgery with the usage of longer screw is the main reasons for worrisome complications. The results of our study are in concurrence with the study of Datir et al, who suggested the $25 \mathrm{~mm}$ screw and $30 \mathrm{~mm}$ screw for upper and midthoracic levels respectively [6]. The mean CL values of our study are comparable to other studies [3, $5,7, \& 11]$. Safe length of screw determined from our study is shown in master table 7.

Sagittal diameter does not influence the pedicle screw choice because it always exceeds pedicle diameter. McLain et al states that, SD varies considerably less from level to level. Only at T1 and T2 did the SD approximate the PD and below T2, the dimension SD grows relatively greater than PD with each level caudally. This resulted in increasingly narrow, oblong pedicles on cross sections in T4-T6 specimens [11]. But this was not noted in our study, the SD was not approximate to PDI at T1-T2 levels and it increased from T1 till T12 in cephalo-caudal direction. Our values of SDI matched with the data of other authors $[7,8,9,11, \& 12]$.

Pedicle length (PL) is partially important dimension because, it defines the minimum length of the screw needed to obtain a grip on the entire pedicle. The pedicle itself seems to be a strong site for screw placement. Krag M.H et al states that, the PL ranges from 40-46\% of the chord length, and then a transpedicular screw should be at least $46 \%$ of the chord length to obtain a grip along the full strength of the pedicle. They have done the study on only T9-T12 vertebrae gave the mean values of 20.18 at T9 and 18.06 at T12 level [5]. In our study the pedicle length was more in mid-thoracic levels compared to upper and lower thoracic levels, with maximum PL found at T8 $6.14 \pm 0.99$ minimum $4.84 \pm 0.85$ at T1 and the PL at T12 is $5.15 \pm 0.64$. Results of PL in our study, statistically and percentage proportion of pedicle in chord length does not match with the values given by Krag M.H. In our study the percentage proportion of PL in CL is ranges from $11-15 \%$.

From the knowledge gained from this study we determined that the transpedicular screw length should be $75 \%$ of the CL and should be 5-6 times the mean value of PL, and the diameter of the screw required at every level is been shown in the Master table 7.

\begin{tabular}{|c|c|c|c|c|c|c|}
\hline \multirow{2}{*}{ Vertebral level } & PDI (Mean) & CL (Mean) & \multirow{2}{*}{$\begin{array}{c}\text { PL } \\
\text { (Mean) }\end{array}$} & \multirow{2}{*}{ \% of PL in CL } & \multicolumn{2}{|c|}{$\begin{array}{c}\text { Screw parameters } \\
\text { after standardization }\end{array}$} \\
\cline { 5 - 7 } & & & & 15 & $5-6$ & 25 \\
\hline T1 & 6.98 & 31.88 & 4.84 & 15 & $5-5.5$ & 25 \\
\hline T2 & 5.62 & 34.33 & 5.23 & 15 & $3.5-4$ & 25 \\
\hline T3 & 4.43 & 36.15 & 5.60 & 15 & $3-3.5$ & 30 \\
\hline T4 & 3.90 & 37.96 & 5.68 & 15 & $3-3.5$ & 30 \\
\hline T5 & 3.93 & 39.26 & 5.86 & 15 & $3.5-4$ & 30 \\
\hline T6 & 4.28 & 41.04 & 5.94 & 14 & $3.5-4$ & 35 \\
\hline T7 & 4.77 & 43.41 & 6.01 & 14 & $3.5-4$ & 35 \\
\hline T8 & 4.95 & 43.74 & 6.14 & 14 & $3.5-4$ & 35 \\
\hline T9 & 5.59 & 44.48 & 6.00 & 13 & & \\
\hline
\end{tabular}




\section{ORIGINAL ARTICLE}

\begin{tabular}{|c|c|c|c|c|c|c|}
\hline T10 & 6.66 & 44.87 & 5.27 & 12 & 5.5 & 35 \\
\hline T11 & 7.55 & 44.93 & 5.19 & 12 & $5.5-6$ & 35 \\
\hline T12 & 7.88 & 45.57 & 5.15 & 11 & $5.5-6$ & 35 \\
\hline & $\begin{array}{l}\text { Master table 7: Showing the determined values of transpedicular } \\
\text { screw parameters after standardization. }\end{array}$
\end{tabular}

\section{*Length is 75\% of chord length (CL) or 5-6 times the length of pedicle (PL). All measurements are in millimeters}

The results of study on thoracic pedicle measurements are very much essential and important for the spinal surgeons, neurosurgeons and orthopedic surgeons who practices transpedicular screw fixation technique. At times choosing the right screw is very important, for which we strongly believe that the statistics of chord length, minimal pedicle diameter and the diameter and length of transpedicular screw determined from our study is very useful.

\section{REFERENCES:}

1. 1. S.Terry Canale, James. H. Beauty, "Campbell's Operative Orthopedics", $11^{\text {th }}$ edition, Vol 2, Mosby Elsevier, 2008; (1732-1733).Text book

2. Suk SI, Kim WJ, Lee SM, Kim JH and Chung ER. "Thoracic pedicle screw fixation in spinal deformities: Are they really safe?" Spine 2001; 26: 2049-2057.

3. David S Bradford, Thomas A. Zdeblick, “ The Spine” Master techniques in orthopaedics, 2nd edition, Lipponcott Williams and Wilkins, 2004; (232). Text book

4. Cinotti, Gianuca MD "Pedicle instrumentation in the thoracic spine: A morphometric and cadaveric study for placement of screws". "Spine" an international journal for the study of the spine, 24(2); WolterKluver/ Lippincott Williams \& Wilkins, Jan 15, 1999, (9114-119).

5. Krag MH, Weaver DL, Beynnon BD and Haugh LD. "Morphometry of the thoracic and lumbar spine related to transpedicular screw placement for surgical spinal fixation". "Spine" 1988; 13 (27-32).

6. Datir, Sandeep.P MS, MRCS, "Morphometric study of the thoracic vertebral pedicle in an Indian population". "Spine" an international journal for the study of the spine, 29(11); Wolter Kluver/ Lippincott Williams \& Wilkins, June 1st 2004, 1174-1181.

7. Michael R. Zindric "Analysis of the morphometric characteristics of the thoracic and lumbar pedicles". "Spine" an international journal for the study of the spine, 12(2); Wolter Kluver/ Lippincott Williams \& Wilkins, 1987.

8. Anastasios G. Christodoulu, Thomas Apostolou et al "Pedicle dimensions of the thoracic and lumbar vertebrae in the Greek population". Journal of Clinical anatomy, vol 18; 2005 (404408)

9. Edward C. Benzel, "Spine surgery, Techniques, Complications avoidance and management, $2^{\text {nd }}$ edition, Vol 1, Elsevier, Churchill Livingstone, 2005 ;( 281). Text book

10. Ebraheim, Nabil A, Rongming, Ahmed, Muhammad, Yeasting, Richard. A, "Projection of the thoracic pedicle and its morphometric analysis". "Spine" an international journal for the study of the spine, 22(3); Wolter Kluver/ Lippincott Williams \& Wilkins, Feb 11997 (233238), full text.

11. McLain, Robert F, Ferrara, Lisa, Kabins, Mark, "Pedicle morphometry in the upper thoracic spine: limits to safe screw placement in older patients" "Spine" an international journal for 


\section{ORIGINAL ARTICLE}

the study of the spine, 27(22); Wolter Kluver/ Lippincott Williams \& Wilkins, Nov 15, 2002 (2467-2471), full text.

12. Chaynes P, Sol JC, Vaysse P, Becue J and Lagarrigue J. "Vertebral pedicle anatomy in relation to pedicle screw fixation: a cadaver study". SurgRadiolAnat 2001; 23:85-90.

\section{AUTHORS:}

1. Gangadhara

\section{PARTICULARS OF CONTRIBUTORS:}

1. Assistant Professor, Department of Anatomy, PES Institute of Medical Sciences and Research.

\section{NAME ADDRESS EMAIL ID OF THE CORRESPONDING AUTHOR:}

Dr. Gangadhara,

Assistant Professor of Anatomy,

PES Institute of Medical Sciences and Research,

Kuppam, Chittoor Dist. - 517425, A.P.

Email - drganga1980@gmail.com

drgangadm@gmail.com

Date of Submission: 28/08/2013.

Date of Peer Review: 29/08/2013.

Date of Acceptance: 30/08/2013.

Date of Publishing: 03/09/2013 